This is an open access article under the CC BY-NC-ND license (https://creativecommons.org/licenses/by-nc-nd/3.0/) Issue III, November 2020

ISSN 2707-9481

ISBN 978-601-323-207-2

https://doi.org/10.31643/2020.024

\author{
Nadezhda V. Vasilenkova \\ Astrakhan State Technical University, Astrakhan, Russia \\ E-mail: Nadine0610@mail.ru \\ ORCID ID 0000-0003-0813-3089
}

\title{
Economic zoning of space as a tool for the development of Russian industry
}

\begin{abstract}
The article is devoted to the description of options for economic zoning of territories as a direction of industrial development. Based on the principles of territorial zoning, the article describes the zones with a special mode of functioning, reveals the features and possibilities of improving the mechanisms of their activity. The work reveals the degree of influence of economic zoning on the functioning of the country's industrial regions, identifies the need to develop zoning tools, considers its main elements: territories of advanced social and economic development, special economic zones, industrial clusters, territories with high scientific and technical potential and industrial parks, their specific features and purposes of creation. In addition, the scientific views of domestic and foreign economists on the feasibility of zoning, its application in a certain industrial region, the features of functioning and legal regulation have been studied.

Keywords: zoning, industrial development, territories of advanced social and economic development, special economic zones, industrial parks, territories with high scientific and technical potential, industrial clusters, technological platforms.
\end{abstract}

Cite this article as: Vasilenkova N. V. (2020). Ekonomicheskoye zonirovaniye prostranstva kak instrument razvitiya promyshlennosti Rossii [Economic zoning of space as a tool for the development of Russian industry]. Challenges of Science. Issue III, p.: 163-169. (In Russian). https://doi.org/10.31643/2020.024

Василенкова Надежда Владиславовна

ФГБОУ ВО «Астраханский государственный технический университет» г. Астрахань, Россия

E-mail: Nadine0610@ mail.ru

ORCID ID 0000-0003-0813-3089

\section{Экономическое зонирование пространства как инструмент развития промышленности России}

\footnotetext{
Абстракт. Статья посвящена описанию вариантов экономического зонирования территорий как направления развития промышленности. Базируясь на принципах зонирования территории, в статье дается характеристика зон с особым режимом функционирования, раскрыты особенности и возможности совершенствования механизмов их деятельности. В работе выявлена степень влияния экономического зонирования на функционирование промышленных регионов страны, определена необходимость развития инструментов зонирования, рассмотрены основные его элементы: территории опережающего социально экономического развития, особые экономические зоны, промышленные кластеры, территории с высоким научно - техническим потенциалом и промышленные парки, их специфичные особенности и цели создания. Кроме того, изучены научные взгляды отечественных и зарубежных экономистов на целесообразность
} 
зонирования, его применения в определенном промышленном регионе, особенности функционирования и нормативно - правового регулирования.

Ключевые слова: зонирование, развитие промышленности, территории опережающего социально экономического развития, особые экономические зоны, индустриальные парки, территории с высоким научно техническим потенциалом, промышленные кластеры, технологические платформы.

\section{Введение}

В связи с существующими факторами (например, ошибки в управлении, коррупция, экономические санкции и т.д.), сдерживающими развитие промышленности Российской Федерации, становится актуально экономическое зонирование территорий. Требует применение экономических инструментов регулирования, и экономическое зонирование пространства может стать хорошей альтернативой для решения представленных задач. Идеи зонирования территорий нашли свое подтверждение в «Стратегии пространственного развития страны на период до 2025 года», основными целями которой являются: повышение конкурентоспособности экономики России и ее субъектов за счет развития эффективных экономических специализаций; ускорение экономического роста государства за счет социально - экономического развития текущих крупных центров экономического роста; обеспечение условий для формирования новых центров экономического роста за счет социально-экономического развития перспективных центров экономического роста. Интерес к экономическому зонированию проявили ученые в науке. Например, Н. Зубаревич указала, на то, что Стратегия ориентируется на модернизацию институтов и стремится к устранению институциональных барьеров (2015).

В свою очередь, П.А. Минакир, А.Н. Демьяненко (2017) отмечают, что зонирование территорий сложное образование с неясными перспективами, а 3. У. Меджидов (2017) подчеркивает необходимость усовершенствования процесса зонирования в связи с осложнившейся макроэкономической ситуацией, вызванной усилением дифференциации регионов страны. Национальный план как основу пространственного развития, предлагает применять А. И. Татаркин (2016). В рамках его научного исследования, рассматриваются федеральные программы, направленные на последовательное развитие приоритетных отраслей промышленности.

За рубежом вопросами пространственного зонирования за рубежом интересовались $\mathrm{S}$. Beugelsdijk, M.J. Klasing, P. Milionis, S.O. Becker, P.H. Egger, M. von Ehrlich (2013, 2019).

Широкий научный интерес к вариативности экономического зонирования свидетельствует о целесообразности его применения для развития промышленности России. Проведенный анализ отечественной литературы выявил необходимости создания инструментов по совершенствованию территорий на основе базовых направлений функционирования промышленности. Такими направлениями промышленности являются увеличение объемов национального производства, создание условий для развития научной мысли, внедрение достижений научно-технического прогресса, усовершенствование отраслевой структуры народного хозяйства и т.д. (Василенкова Н.В., 2017). В процессе исследования, выявлены проблемы, которые вызывают острую необходимость зонирования территорий: экономические, к ним можно отнести монопрофильность территорий страны, низкая диверсификация экономики, высокая значимость трудовых ресурсов от градообразующего предприятия; социальные, к ним относятся: низкие доходы населения, его сокращение, отток и в целом невысокое качество жизни; инфраструктурные: высокий износ социальной и инженерной инфраструктуры, высокая экологическая нагрузка на территории и т.д. В качестве решения представленных проблем, выступает зонирование как инструмент развития отдельных территорий и промышленных регионов на основе применения специальных режимов, льгот и преференций, является актуальным, что и предопределило цель данной работы. Для создания экономического, промышленного роста региона целесообразно применять комплексный подход учитывающий политику точечного развития с учетом конкурентных преимуществ, основываясь на кластерном подходе повышать инновационый потенциал территорий.

\section{Методы}

Целью статьи является исследование сущности и экономического содержания понятий «территории опережающего социально - экономического развития», «особые экономические зоны», «индустриальные парки», «территории с высоким научно - техническим потенциалом», «промышленные кластеры» на основе выделения имманентных признаков и особенностей. С 
применением методов системного анализа в работе рассмотрен понятийный аппарат экономического зонирования, основные его организационные структуры, показано их место в развитии промышленности, выявлены факторы сдерживающие развитие и повсеместное применение представленного инструмента. Инструментарий работы включает методы сравнительного и структурного анализа, логические приемы классификации, сопоставления и исключения, исследование нормативноправой базы. Предметом анализа выступает сущность, содержание, отличительные признаки и особенности функционирования структурных элементов пространственного зонирования территорий промышленных регионов. Ожидаемый результат развитие теоретического базиса экономического зонирования территорий.

\section{Обсуждение}

В своих работах В. П. Шестак (2017), отмечает интенсивное формирование экономико технологического пространства, под которым понимается «ограниченная нормативной правовой оболочкой часть экономического пространства, в которой сконцентрированы институты развития, совокупность промышленных объектов и промышленных инфраструктур, включая структуры монополий, обеспечивающая цели промышленной политики России по формированию высокотехнологичной, конкурентоспособной импортозамещающей промышленности». Именно создание такого пространства в Российской Федерации может обеспечить переход экономики государства к инновационному типу развития, повысить результативность в промышленности и т.д. Е. Н. Лукаш и Е. М. Бухарова (2019) считают формирование территорий с особыми правовыми решениями одним из приоритетных направлений государственной поддержки регионам России, а также создание благоприятных условий функционирования и развития региональной промышленности.

В экономико - технологическое пространство можно включить следующие элементы:

1. Субъекты инфраструктур, управляемых естественными монополиями (транспортных, авиа - речных и морских портов, добывающих и т.д.);

2. Территории опережающего социально - экономического развития (ТОСЭР), представляющие собой экономическую зону с упрощенными административными процедурами, налоговыми льготами, другими приференциями и могут быть размещены на территории со специально созданной самостоятельной инфраструктурой или же в целом охватывать город, используя имеющуюся производственную, логистическую и складскую структуру (например, моногород).

Данные зоны формируются по решению Правительства сроком до 70 лет, который может быть при необходимости продлен ${ }^{1}$. Резидентами ТОСЭР может быть предприятия, внесшие 20 млн. рублей и занимающие любую, удобную для себя в рамках зоны, территориальную локацию. Ф. Ф. Шарипов и А. В. Садков (2016) рассматривая территории опережающего социально - экономического развития как инструмент привлечения инвестиций в производственную систему регионов, отмечают особый правовой режим предпринимательской деятельности в таких зонах. Н. Д. Воронов и И. С. Гилева (2018) другой отличительной особенностью считают возможность проводить подакцизные товары и т.д. Основная цель создания зон - это развитие территорий, на которых они находятся. Особенность зон заключается еще и в том, что создаются они для определенной экономической деятельности, под определенного инвестора с учетом географического и социально - экономического расположения региона. Таким образом, территории опережающего социально - экономического развития предполагают расширенную сферу деятельности резидентов и увеличивают, тем самым, развитие инвестиционной инфраструктуры региона.

В. П. Чичканов (2018) выявляет возможность территории опережающего социально экономического развития представлять целые муниципальные образования, развитие которых входит, в первую очередь, в перечень обязанностей государства.Таким образом, стимулирование режима налогообложения выполняет следующие функции: повышение экономической привлекательности определенных территорий; поддержка и развитие бизнес - структур; создание условий новому бизнесу и укреплению его потенциалу.

1 О территориях опережающего социально-экономического развития в Российской Федерации [электронный ресурс]: Федеральный закон от 29 декабря 2014 г. № 473-Ф3 (в ред. от 27 декабря 2018 г.). Доступ из справ.-правовой системы «КонсультантПлюс». 
На основании проведенного анализа, становится возможным выявление общих черт государственного регулирования вопросов пространственного зонирования промышленных регионов на основе социально - экономического развития:

1. Нормативно - закрепленные ограничения органов власти (исполнительной и муниципальной) в правах надзора и контроля над деятельностью ТОСЭР управляющим компаниям;

2. Определение вида деятельности и конкретной территории на основании интересов крупных отечественных и/ или зарубежных инвесторов.

3. Высокая бюджетная доходность от деятельности территорий опережающего социально - экономического развития, создание новых рабочих мест, развитие нового производства и эффективное функционирование уже имеющегося, расширение инфраструктуры и развитие промышленного региона в целом.

4. Активная разработка и последующее внедрение новых технологий в производственный процесс, применение автоматической регистрацией и электронного декларирования продукции, цифровые технологии удаленного выпуска.

Таким образом, диверсификация экономики за счет развития специализированных новых производств и уникальных технологий, поддержка бизнеса, повышение занятости за счет привлечения на производства местного населения, рост числа объектов социальной инфраструктуры и повышение в целом инвестиционной привлекательности территорий - это то, что будет обеспечено за счет продвижения ТОСЭР на всех территориях Российской Федерации.

3. Особые экономические зоны ${ }^{2}$. Основной целью создания стала необходимость устойчивого развития основных отраслей промышленности регионов нашей страны, как справедливо заметил А. В. Заступов (2019), главный интерес государства при формировании экономических зон - это привлечение инвесторов, в первую очередь зарубежных, увеличение поступлений в бюджет, развитие импортозамещения, а также рост количества рабочих мест и промышленных технологий. Основной идей формирования ОЭЗ является сосредоточение точек роста на конкретных, выбранных государством территориях путем привлечения инвестиций на льготных основаниях (Терентьева Е.А., Василенкова Н.В., 2015). За счет централизации всех производственных циклов, предоставляемых льгот и преференций, организация деятельности на территории ОЭЗ является наиболее эффективной, чем за ее пределами, однако предусматривает значительные капиталовложения, что не всегда приемлемо для бизнеса на этапе становления.

Таким образом, особые экономические зоны признаны перспективным институтом развития отраслей народного хозяйства и национальной экономики в целом. Применение данного института предполагает повысить экономический интерес резидентов и привлечь дополнительные инвестиции в промышленные отрасли. Однако следует отметить, что при создании ОЭЗ необходимо учесть степень риска, а также решить проблемы, связанные в Российской Федерации со становлением системы экономических институтов развития. Создание кластеров, обладающих конкурентоспособностью: поддерживает развитие регионов, на территории которых они расположены; выступает основным условием углубленной экономической межрегиональной интеграции; служит ускорителем для размещения тех производств и объектов инфраструктуры, которые содействуют развитию кластера. С точки зрения специфичности кластера как экономической системы он имеет внешнее окружение и внутреннюю среду функционирования (Василенкова Н.В., 2018).

4. Промышленные кластеры - совокупность субъектов деятельности в сфере промышленности, связанных отношениями в указанной сфере вследствие территориальной близости и функциональной зависимости и размещенных на территории одного или нескольких субъектов РФ (Боев А.Г., 2020).

5. Территории с высоким научно - техническим потенциалом. И. А. Кокорев (2011) отмечает, что структура территории с высоким научным потенциалом имеет ряд особенностей по сравнению с обычным поселением или регионом и накладывает отпечаток на процессы формирования, функционирования и развития рынка труда на этих территориях.

2 Федеральный закон от 22 июля 2005 г. N 116-Ф3 "Об особых экономических зонах в Российской Федерации" Система ГАРАНТ: http://base.garant.ru/12141177/\#ixzz6dsYEH6TR 
Наукограды - наиболее характерное проявление территорий с высокой концентрацией научного потенциала важно отметить, что «анализ процесса формирования и развития государственной политики в отношении наукоградов дает основание характеризовать этот процесс в целом как противоречивый и непоследовательный. Основным противоречием является резкое расхождение между официальными документами и практикой их реализации. Поэтому говорить о государственной политике в отношении наукоградов, как о целостном явлении, можно лишь с определенной долей условности». Таким образом, можно говорить о необходимости дальнейшего развития государственной поддержки территорий с высоким научным потенциалом, на всех уровнях государственного устройства.

6. Промышленные парки - представляют собой совокупность объектов промышленной инфраструктуры, предназначенную для создания нового промышленного или модернизации имеющегося производства, которые могут расчитывать на определенный федеральным законодательством круг привелегий и преимуществ: поддержка администрации регионов и государства в связи с заинтересованностью данных лиц в загруженности промышленных парков; широкий доступ к развитой инфраструктуре резидентов промышленного парка (инженерные коммуникации, транспортная логистика и т.д.); государство оказывает помощь резидентам, субсидируя покупку, например, оборудования до $50 \%$ от его стоимости; помощь резидентам в сбыте продукции, на основе сырьевой кооперации. Таким образом, промышленные парки создают условия для развития деятельности их резидентов, тем самым, осуществляя вклад в промышленность Российской Федерации.

7. Инжиниринговые центры являются юридическими лицами, сформированные на промышленных предприятиях для оказания инженерно - консультационных услуг по подготовке производственного процесса.

8. Технологические платформы - это коммуникационный инструмент, с участием всех интересующихся сторон (общества, бизнеса и государства), направленный на создание перспективных технологий и дополнительных ресурсов на проведение разработок

9. Проектные консорциумы - это еще один перспективный способ взаимодействия участников инновационной системы, основанный на территориальной привязке (кластеры) и наделенный целями и задачами (технологическая платформа). Проектные консорциумы включают предприятия малого и среднего бизнеса, инжиниринговые компании, крупные компании с государственным участием, производящие новые технологии в промышленности.

\section{Выводы}

Подводя итог, проведенному исследованию, необходимо отметить, что среди ученых и практиков отсутствует единое мнение об эффективности применения зонирования в целях развития промышленности. Наиболее эффективным может стать применения опыта функционирования зон, которые показали высокий результат, например, особая экономическая зона «Лотос». Эффективными признаются зоны, сводный показатель которых составил более $80 \%$, достаточно эффективными - от $40 \%$ до $80 \%$, неэффективными - менее $40 \%$. Особая экономическая зона «Лотос» расположилась в середине списка эффективных особых экономических зон с показателем 92\% за 2019 год (+9\% по сравнению с 2018 годом) и 82\% накопленным итогом за весь период работы. Таким образом, проведенный анализ деятельности зон с особым режимом предполагает получения высокого экономического эффекта для промышленности и экономики России в целом.

Ссылка на данную статью: Василенкова Н. В. (2020) Экономическое зонирование пространства как инструмент развития промышленности России. Материалы Международной практической интернет-конференции «Актуальные проблемы науки» [Challenges of Science]. Выпуск III, стр. 163-169. https://doi.org/10.31643/2020.024 


\section{Литературы}

[1] Becker S. O., Egger P. H., von Ehrlich M. Absorptive capacity and the growth and investment effects of regional transfers: A regression discontinuity design with heterogeneous treatment effects // American Economic Journal: Economic Policy.2013. - No. 5 (4). - P. 29-77. - DOI: 10.1257/pol.5.4.29.

[2] Beugelsdijk S., Klasing M. J., Milionis P. Value diversity and regional economic development // Scandinavian Journal of Economics. - 2019. - Vol. 121, Iss. 1. - P. 153-181. - DOI: 10.1111/sjoe.12253.

[3] Боев А. Г. К вопросу о содержании и дифференциации понятий промышленный комплекс, кластер и индустриальный парк // Организатор производства. 2020. T.28. №2. С. 7-17 DOI: 10.25987/VSTU.2020.97.45.001

[4] Василенкова Н.В. Направления совершенствования промышленной политики России // В сборнике: Наука и практика - 2017. Материалы Всероссийской междисциплинарной научной конференции. Под общей редакцией Н.Т. Берберовой, А.В. Котельникова. 2017. С. 186-187.

[5] Василенкова Н.В. Роль промышленной кластеризации в развитии регионов // В сборнике: Формирование и реализация стратегии устойчивого экономического развития Российской Федерации. Сборник статей VIII Международной научно-практической конференции. 2018. С. 38-40.

[6] Воронов Н.Д., Гилева И.С. Особые экономические зоны как механизм развития экономического потенциала региона // Управление региональным развитием: проблемы, возможности, перспективы развития: сборник научных статей / отв. Ред. Е.И. Ильина. Чебоксары: Чувашский гос. пед. университет, 2018. 480 с

[7] Заступов А.В. Территории экономического развития как площадки для привлечения инвестиций Наука XXI века: актуальные направления развития. 2019. № 2-1. С. 139-142.

[8] Зубаревич Н.В. Стратегия пространственного развития после кризиса: от больших проектов к институциональной модернизации // Журнал новой экономической ассоциации. 2015. № 2 (26). С. 226-230

[9] Кокорев И.А. Структурные составляющие территории с высоким научным потенциалом// Вестник евразийской науки. 2011 № 2(7).

[10] Лукаш Е.Н., Бухарова Е.М. Анализ влияния территорий с особыми правовыми режимами на региональное развитие России: эконометрический подход //Проблемы прогнозирования. 2019. № 2 (173). С. 152-162.

[11] Меджидов 3.У. Сравнительный анализ использования территорий с особым экономическим статусом в Российской Федерации // Вестник Волжского университета им. В.Н. Татищева. 2017. Т. 1. № 4. С. 254-262

[12] Минакир П.А., Демьяненко А.Н. Экономическое пространство современной России и подходы к его исследованию (статья первая) // Регионалистика. 2017. Т. 4. № 1. С. 5-14.

[13] О территориях опережающего социально-экономического развития в Российской Федерации [электронный ресурс]: Федеральный закон от 29 декабря 2014 г. № 473-Ф3 (в ред. от 27 декабря 2018 г.). Доступ из справ. правовой системы «КонсультантПлюс».

[14] Татаркин А.И. Региональная направленность экономической политики Российской Федерации как института пространственного обустройства территорий // Экономика региона. 2016. Т. 12. № 1. С. 9-27.

[15] Терентьева Е.А., Василенкова Н.В. Особые экономические зоны в процессе кластеризации // Вопросы региональной экономики. 2015. № 2 (23). С. 56-60.

[16] Федеральный закон от 22 июля 2005 г. N 116-Ф3 "Об особых экономических зонах в Российской Федерации" Система ГАРАНТ: http://base.garant.ru/12141177/\#ixzz6dsYEH6TR

[17] Чичканов В. П., Беляевская-Плотник Л. А. Территории опережающего развития в контексте обеспечения экономической безопасности макрорегиона // Экономика региона. - 2018. - Т. 14, вып. 1. - С. 227-242. - DOI: $10.17059 / 2018-1-18$.

[18] Шарипов Ф.Ф., Садков А.В. Создание ТОСЭР как инструмент привлечения инвестиций в производственную инфраструктуру регионов РФ // Вестник университета. 2016. № 4. С. 109-115.

[19] Шестак В.П. Промышленная политика и макроэкономическое регулирование// Экономика. Налоги. Право. 2017. Т. 10. № 3. C. 67-77.

\section{References}

[1] Becker S. O., Egger P. H., von Ehrlich M. Absorptive capacity and the growth and investment effects of regional transfers: A regression discontinuity design with heterogeneous treatment effects // American Economic Journal: Economic Policy. 2013. - No. 5 (4). - P. 29-77. - DOI: 10.1257/pol.5.4.29. (In English).

[2] Beugelsdijk S., Klasing M. J., Milionis P. Value diversity and regional economic development // Scandinavian Journal of Economics. - 2019. - Vol. 121, Iss. 1. - P. 153-181. - DOI: 10.1111/sjoe.12253. (In English).

[3] Boyev A. G. K voprosu o soderzhanii i differentsiatsii ponyatiy promyshlennyy kompleks, klaster i industrial'nyy park [On the content and differentiation of the concepts of industrial complex, cluster and industrial park] // Organizator proizvodstva. 2020. T.28. №2. S. 7-17 DOI: 10.25987/VSTU.2020.97.45.001 (In Russian).

[4] Vasilenkova N.V. Napravleniya sovershenstvovaniya promyshlennoy politiki Rossii [Directions of improving the industrial policy of Russia] // V sbornike: Nauka i praktika - 2017. Materialy Vserossiyskoy mezhdistsiplinarnoy nauchnoy konferentsii. Pod obshchey redaktsiyey N.T. Berberovoy, A.V. Kotel'nikova. 2017. S. 186-187. (In Russian).

[5] Vasilenkova N.V. Rol' promyshlennoy klasterizatsii $\mathrm{v}$ razvitii regionov [The role of industrial clustering in the development of regions] // V sbornike: Formirovaniye i realizatsiya strategii ustoychivogo ekonomicheskogo razvitiya Rossiyskoy Federatsii. Sbornik statey VIII Mezhdunarodnoy nauchno-prakticheskoy konferentsii. 2018. S. 38-40. (In Russian).

[6] Voronov N.D., Gileva I.S. Osobyye ekonomicheskiye zony kak mekhanizm razvitiya ekonomicheskogo potentsiala regiona [Special economic zones as a mechanism for the development of the economic potential of the region] // Upravleniye regional'nym razvitiyem: problemy, vozmozhnosti, perspektivy razvitiya: sbornik nauchnykh statey / otv. Red. Ye.I. Il'ina. Cheboksary: Chuvashskiy gos. ped. universitet, 2018, p. 480. (In Russian).

[7] Zastupov A.V. Territorii ekonomicheskogo razvitiya kak ploshchadki dlya privlecheniya investitsiy [Territories of 


\section{Materials of International Practical Internet Conference "Challenges of Science”}

economic development as a platform for attracting investments]. Nauka XXI veka: aktual'nyye napravleniya razvitiya. 2019. № 2-1. S. 139-142. (In Russian).

[8] Zubarevich N.V. Strategiya prostranstvennogo razvitiya posle krizisa: ot bol'shikh proyektov k institutsional'noy modernizatsii [Spatial development strategy after the crisis: from large projects to institutional modernization] // Zhurnal novoy ekonomicheskoy assotsiatsii. 2015. № 2 (26). S. 226-230 (In Russian).

[9] Kokorev I.A. Strukturnyye sostavlyayushchiye territorii s vysokim nauchnym potentsialom [Structural constituents of the territory with high scientific potential] // Vestnik yevraziyskoy nauki. 2011 № 2(7). (In Russian).

[10] Lukash Ye.N., Bukharova Ye.M. Analiz vliyaniya territoriy s osobymi pravovymi rezhimami na regional'noye razvitiye Rossii: ekonometricheskiy podkhod [Analysis of the influence of territories with special legal regimes on the regional development of Russia: an econometric approach] // Problemy prognozirovaniya. 2019. № 2 (173). S. 152-162. (In Russian).

[11] Medzhidov Z.U. Sravnitel'nyy analiz ispol'zovaniya territoriy s osobym ekonomicheskim statusom v Rossiyskoy Federatsii [Comparative analysis of the use of territories with a special economic status in the Russian Federation] // Vestnik Volzhskogo universiteta im. V.N. Tatishcheva. 2017. T. 1. № 4. S. 254-262 (In Russian).

[12] Minakir P.A., Dem'yanenko A.N. Ekonomicheskoye prostranstvo sovremennoy Rossii i podkhody k yego issledovaniyu (stat'ya pervaya) [. Economic space of modern Russia and approaches to its study (article 1)] // Regionalistika. 2017. T. 4. № 1. S. 5-14. (In Russian).

[13] O territoriyakh operezhayushchego sotsial'no-ekonomicheskogo razvitiya v Rossiyskoy Federatsii [On the territories of advanced social and economic development in the Russian Federatio]. [Elektronnyy resurs]: Federal'nyy zakon ot 29 dekabrya 2014 g. № 473-FZ (v red. ot 27 dekabrya 2018 g.). Dostup iz sprav. - pravovoy sistemy «Konsul'tantPlyus». (In Russian).

[14] Tatarkin A.I. Regional'naya napravlennost' ekonomicheskoy politiki Rossiyskoy Federatsii kak instituta prostranstvennogo obustroystva territoriy [Regional orientation of the economic policy of the Russian Federation as an institution of spatial development of territories] // Ekonomika regiona. 2016. T. 12. № 1. S. 9-27. (In Russian).

[15] Terent'yeva Ye.A., Vasilenkova N.V. Osobyye ekonomicheskiye zony v protsesse klasterizatsii [Special economic zones in the process of clustering] // Voprosy regional'noy ekonomiki. 2015. № 2 (23). S. 56-60. (In Russian).

[16] Federal'nyy zakon ot 22 iyulya 2005 g. N 116-FZ "Ob osobykh ekonomicheskikh zonakh v Rossiyskoy Federatsii" [On special economic zones in the Russian Federation] Sistema GARANT: http://base.garant.ru/12141177/\#ixzz6dsYEH6TR (In Russian)

[17] Chichkanov V. P., Belyayevskaya-Plotnik L. A. Territorii operezhayushchego razvitiya v kontekste obespecheniya ekonomicheskoy bezopasnosti makroregiona [Territories of advanced development in the context of ensuring the economic security of the macroregio] // Ekonomika regiona. - 2018. - T. 14, vyp. 1. - S. 227-242. - DOI: 10.17059/2018-1-18. (In Russian).

[18] Sharipov F.F., Sadkov A.V. Sozdaniye TOSER kak instrument privlecheniya investitsiy v proizvodstvennuyu infrastrukturu regionov RF [Establishment of TASED as a tool for attracting investments in the industrial infrastructure of the regions of the Russian Federation] // Vestnik universiteta. 2016. № 4. S. 109-115. (In Russian).

[19] Shestak V.P. Promyshlennaya politika i makroekonomicheskoye regulirovaniye [Industrial policy and macroeconomic regulation] // Ekonomika. Nalogi. Pravo. 2017. T. 10. № 3. S. 67-77. (In Russian) 